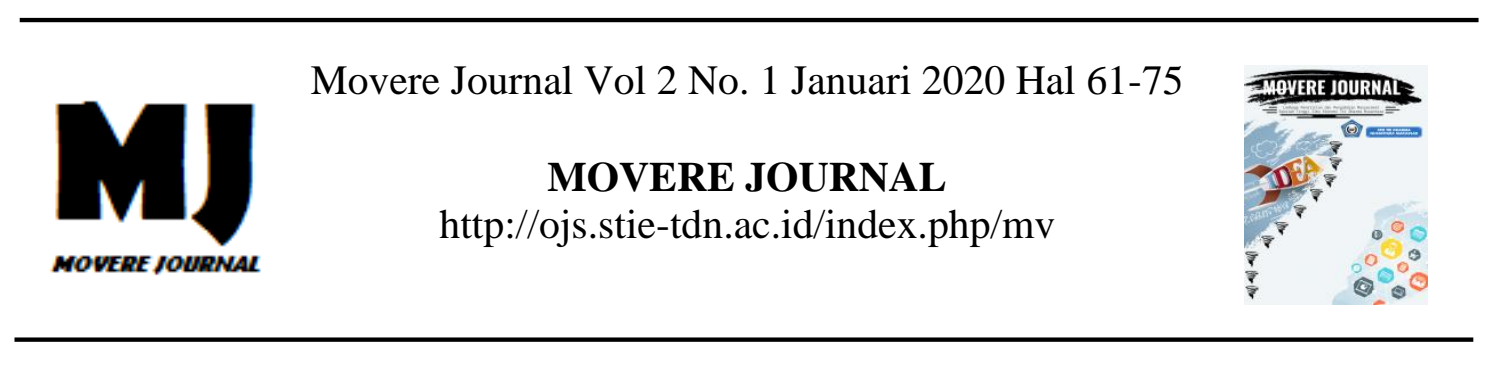

\title{
FAKTOR-FAKTOR YANG MEMPENGARUHI INTENSI KNOWLEDGE SHARING PADA PT. BANK SULSELBAR KANTOR PUSAT MAKASSAR
}

\author{
Panus \\ Institut Bisnis dan Keuangan Nitro Makassar
}

\begin{abstract}
Abstrak: Metode analisis yang digunakan dalam penelitian adalah analisis regresi linear berganda, analisis instrumen terdiri dari uji validitas dan uji reliabilitas, uji hipotesis penelitian terdiri dari uji parsial (uji t), dan uji asumsi klasik yang terdiri dari uji normalitas dan uji multikolinearitas dengan menggunakan program SPSS (Statistic Program for Social Science) versi 21. Sampel yang digunakan pada penelitian ini yaitu karyawan PT. Bank Sulselbar Kantor Pusat Makassar yang berjumlah 62 orang. Hasil penelitian menunjukkan bahwa mekanisme transfer ilmu berpengaruh secara positif dan tidak signifikan terhadap intensi knowledge sharing, sarana pendukung berpengaruh secara positif dan signifikan terhadap intensi knowledge sharing, budaya berpengaruh secara positif dan tidak signifikan terhadap intensi knowledge sharing, motivasi berpengaruh secara negatif dan tidak signifikan terhadap intensi knowledge sharing, dan faktor yang paling dominan mempengaruhi intensi knowledge sharing adalah sarana pendukung.
\end{abstract}

Keyword: Mekanisme Transfer Ilmu, Sarana Pendukung, Budaya, Motivasi, dan Intensi Knowledge Sharing

\section{PENDAHULUAN}

Pengetahuan yang dimiliki oleh suatu organisasi merupakan aset yang sangat berharga (Lopez dkk, 2011) dan merupakan aset yang tak kasat mata atau intangible asset (Goel dkk, 2010), pengetahuan juga merupakan sumber daya internal perusahaan yang paling bernilai, unik, sulit digantikan, dan sulit ditiru (Kaplan dkk, 2001). Dengan pengetahuan dan kemampuan untuk menciptakan pengetahuan baru, perusahaan dapat menggunakan dan mentransformasikan sumber daya lain. Melalui knowledge management, pengetahuan yang dimiliki seorang karyawan tetap tinggal dan menjadi aset perusahaan sekalipun secara fisik mereka telah meninggalkan perusahaan.

Knowledge sharing merupakan pertukaran pengetahuan antar dua individu yaitu satu orang yang mengkomunikasikan pengetahuan, sedangkan seorang lainnya mengasimilasi pengetahuan tersebut, fokus utamanya adalah karyawan mampu menjelaskan, mengkodekan dan mengkomunikasikan pengetahuan kepada orang lain, kelompok, dan khususnya kepada perusahaan (Jacobson, 2006).

Szulanski (2001) bahwa ada empat faktor yang mempengaruhi knowledge sharing saat ini adalah: mekanisme transfer ilmu, sarana pendukung, budaya dan motivasi. Keempat variabel ini sangat 
berpengaruh terhadap pelaksanaan knowledge sharing yang dilakukan oleh perusahaan. Tujuan perusahaan melakukan knowledge sharing adalah untuk melakukan transfer informasi dan pengetahuan mengenai perbankan, karena aliran informasi yang baik dapat menjadi salah satu faktor kunci keberhasilan perusahaan.

\section{Rumusan Masalah}

Berdasarkan latar belakang penelitian tersebut, maka rumusan masalah yang diajukan dalam penelitian ini adalah:

1. Apakah mekanisme transfer ilmu berpengaruh terhadap intensi knowledge sharing pada karyawan PT. Bank Sulselbar Kantor Pusat Makassar?

2. Apakah sarana pendukung berpengaruh terhadap intensi knowledge sharing pada karyawan PT. Bank Sulselbar Kantor Pusat Makassar?

3. Apakah budaya berpengaruh terhadap intensi knowledge sharing pada karyawan PT. Bank Sulselbar Kantor Pusat Makassar?

4. Apakah motivasi berpengaruh terhadap intensi knowledge sharing pada karyawan PT. Bank Sulselbar Kantor Pusat Makassar?

5. Faktor apakah yang paling dominan mempengaruhi intensi knowl sharing pada PT. Bank Sulselbar Kantor Pusat Makassar?

\section{TELAAH LITERATUR DAN PENGEMBANGAN HIPOTESIS}

\section{Knowledge Management}

Menurut Wikipedia, Knowledge Management merupakan suatu rangkaian kegiatan yang digunakan oleh organisasi atau perusahaan untuk mengidentifikasi, menciptakan, menjelaskan, dan mendistribusikan pengetahuan untuk digunakan kembali, diketahui, dan dipelajari di dalam organisasi. Kegiatan ini biasanya terkait dengan objektif organisasi dan ditujukan untuk mencapai suatu hasil tertentu seperti pengetahuan bersama, peningkatan kinerja, keunggulan kompetitif, atau tingkat inovasi yang lebih tinggi.

\section{Knowledge Sharing}

Hooff dan Ridder (2004) memberikan pemahaman mengenai knowledge sharing sebagai proses dimana para individu secara mutual mempertukarkan pengetahuan mereka (baik pengetahuan tacit dan explisit), dan akhirnya secara terpadu dapat menciptakan pengetahuan baru.

\section{METODE PENELITIAN}

\section{Lokasi dan Waktu Penelitian}

Penelitian ini dilaksanakan pada PT. Bank Sulselbar Kantor Pusat Makassar yang terletak di Jl. Dr. Sam Ratulangi No.16 Makassar selama kurang lebih 1 (satu) bulan.

\section{Jenis dan Sumber Data Jenis Data}

Adapun jenis data yang digunakan dan dibutuhkan dalam penelitian ini adalah:

a. Data kualitatif yaitu data yang diperoleh dari penyebaran kuesioner kepada responden pada PT. Bank Sulselbar Kantor Pusat Makassar.

b. Data kuantitatif yaitu data yang berupa jumlah karyawan pada PT. Bank Sulselbar Kantor Pusat Makassar.

\section{Sumber Data}

Yang digunakan dalam penelitian ini dikelompokkan menjadi 2 (dua) yaitu: 
a. Data primer adalah data yang diperoleh dengan jalan menyebarkan selebaran kuesioner kepada responden mengenai faktor-faktor yangmempengaruhi intensi knowledge sharing pada PT. Bank Sulselbar Kantor Pusat Makassar.

b. Data sekunder adalah data yang diperoleh dari PT. Bank Sulselbar Kantor Pusat Makassar.

\section{Teknik Pengumpulan Data}

\section{Penelitian Pustaka (Library Research)}

Suatu pengumpulan data atau informasi dengan mempelajari referensi, buku-buku dan literatur yang berkaitan dengan penelitian guna mendapatkan landasan untuk membahas permasalahan yang diteliti.

\section{Penelitian Lapangan (Field Recearch)}

Angket atau kuesioner yaitu teknik pengumpulan data melalui formulir-formulir yang berisi pertanyaan atau pernyataan yang diajukan secara tertulis pada seseorang atau sekumpulan orang untuk mendapatkan jawaban atau tanggapan dan informasi yang diperlukan oleh peneliti.

\section{Definisi Operasional Penelitian}

Dalam penelitian ini, digunakan beberapa istilah sehingga didefinisikan secara operasional agar menjadi petunjuk dalam penelitian ini. Definisi operasional tersebut antara lain

1. Mekanisme transfer ilmu (X1) merupakan penggambaran tingkat efektifitas pendistribusian pengetahuan yang baik, dengan indikator:
a. SDM
mengandalkan
proses interaksi
komunikasi antar pegawai.

b. SDM membagi informasi sebagai sumber pengetahuan.
c. SDM membagi informasi menyangkut program kerja inti.

2. Sarana pendukung $\left(\mathrm{X}_{2}\right)$ merupakan sarana-sarana yang disediakan oleh perusahan dalam rangka memudahkan transfer pengetahuan yang dilakukan antar karyawan, dengan indikator:

a. Penerapan system informasi mendukung dalam pelaksanaan berbagai pengetahuan.

b. Informasi melalui website internet dapat mempermudah menyelesaikan pekerjaan.

c. Internet dapat dijadikan sebagai sarana komunikasi yang efektif dalam berbagai ilmu pengetahuan.

3. Budaya merupakan (X3) kumpulan nilai-nilai yang harus selalu menjadi pegangan karyawan dalam perusahaan untuk memahami tindakan yang mana dipertimbangkan untuk diterima dan yang tidak diterima, dengan indikator:
a. Pimpinan memberikan
kebebasan berpendapat sesuai koridor atau aturan.
b. Pimpinan memberikan kebebasan berinovasi sesuai tugas pokok.
c. Pimpinan memberikan dorongan kepada karyawan agar memiliki inisiatif dalam mengembangkan perusahaan.

4. Motivasi (X4) merupakan faktorfaktor yang memotifasi karyawan untuk mau membagi pengetahuan yang dimiliki, dengan indikator: 

a. Kesesuaian gaji dengan kebutuhan karyawan.
b. Memberikan kesempatan bagi karyawan untuk mengikuti promosi jabatan.
c. Tunjangan untuk meningkatkan kesejahteraan karyawan dan keluarganya.

5. Intensi knowledge sharing karyawan (Y) merupakan proses dimana individu secara kolektif dan interaktif memperbaiki sebuah pemikiran, gagasan atau saran sesuai dengan petunjuk dari pengalaman individu, adapun indikatornya yaitu:

$\begin{array}{lrr}\text { a.Program knowledge sharing } \\ \text { dapat meningkatkan kinerja } \\ \text { karyawan. } \\ \text { b.Knowledge } & \text { sharing } & \text { telah } \\ \text { mendukung } & \text { kepuasan kerja } \\ \text { karyawan. } & & \\ \text { c. Knowledge sharing yang } \\ \text { dilakukan } & \text { meningkatkatkan } \\ \text { skill dan } & \text { keterampilan } \\ \text { karyawan. } & \end{array}$

\section{Analisis Data}

Untuk membuktikan hipotesis yang telah dikemukakan maka digunakan metode analisis sebagai berikut :

\section{Uji Instrumen}

\section{a. Uji Validitas}

Uji validitas akan dilakukan dengan metode Pearson, yaitu dengan mengkorelasikan skor butir pada kuesioner dengan skor totalnya. Jika nilai koefisien korelasinya $<0,05$ maka butir pertanyaan tersebut dapat dikatakan valid. Uji validitas ini menggunakan bantuan program SPSS (Sugiono, 2012 : 117).

$$
\begin{aligned}
& \text { b. Uji Reliabilitas } \\
& \text { Uji reliabilitas dapat dilakukan } \\
& \text { dengan menggunakan bantuan } \\
& \text { program SPSS, yang akan }
\end{aligned}
$$

memberikan fasilitas untuk mengukur reliabilitas dengan uji statistik Cronbach Alpha $(\alpha)$. Suatu konstruk atau variable dikatakan reliable jika memberikan nilai Cronbanch Alpha > 0,60 (Ghozali, $2006:$ 133).

\section{Analisis Regresi Linear Berganda}

Untuk melihat sejauh mana pengaruh faktor-faktor yang mempengaruhi intense knowledge sharing. Data diolah menggunakan komputer dengan bantuan program SPSS.

$$
\mathrm{Y}=\mathrm{a}+\mathrm{b}_{1} \mathrm{X}_{1}+\mathrm{b}_{2} \mathrm{X}_{2}+\mathrm{b}_{3} \mathrm{X}_{3}+\mathrm{b}_{4} \mathrm{X}_{4}+\mathrm{e}
$$

\section{Pengujian Hipotesis}

Uji parsial (Uji t)

Uji ini adalah untuk mengetahui apakah pengaruh masing-masing variable bebas terhadap variable terikat bermakna atau tidak. Pengujian dilakukan dengan membandingkan antara nilai thitung masing-masing variabel bebas dengan nilai table dengan derajat kesalahan $5 \%(=0.05)$ apabila nilai thitung > tabel, maka variable bebasnya memberikan pengaruh bermakna terhadap variable terikat.

\section{Uji Asumsi Klasik}

\section{a. Uji Normalitas}

Uji normalitas bertujuan untuk mengetahui apakah data yang diperoleh berdistribusi normal atau tidak. Uji normalitas yang dilakukan terhadap sampel dilakukan dengan menggunakan Probability Plot. jika sebaran data mendekati garis normal atau di sekitar garis diagonal dan mengikuti arah garis diagonal, sehingga dapat disimpulkan bahwa data mempunyai distribusi sangat normal. (Ghozali, 2007:140).

b. Uji Multikoliniearitas

Multikoloniearitas berarti terjadi interkorelasi antara variable independent yang menunjukkan 
adanya lebih dari satu hubungan linear yang signifikan. Berdasarkan hasil analisis collinearity statistic diketahui bahwa VIF (Variance Inflation Factor) berjeda pada kisaran 0 sampai 10. (Ghozali, 2007 : 126).

\section{HASIL PENELITIAN DAN PEMBAHASAN}

\section{Hasil Penelitian}

\section{Gambaran Umum Responden}

Penyajian data mengenai identitas responden disini, yaitu untuk memberikan gambaran tentang keadaan data individu dari responden, yang diidentifikasi berdasarkan jenis kelamin, usia responden, jenjang pendidikan, serta lama kerja yang dapat dijelaskan pada uraian berikut ini :

a. Responden Berdasarkan Jenis Kelamin

Dari 62 responden yang dikumpulkan menunjukkan bahwa responden berjenis kelamin laki-laki sebanyak 34 orang atau $55 \%$ dan responden berjenis kelamin perempuan sebanyak 28 orang atau 45\%. Dapat disimpulkan bahwa PT. Bank Sulselbar Kantor Pusat Makassar yang dominan ialah karyawan berjenis kelamin laki-laki.

Data responden berdasarkan umur

\begin{tabular}{|c|c|c|c|c|c|}
\hline \multicolumn{7}{|c|}{ JENIS KELAMIN } \\
\hline \multicolumn{2}{|c|}{} & Frequency & Percent & $\begin{array}{c}\text { Valid } \\
\text { Percent }\end{array}$ & $\begin{array}{c}\text { Cumulative } \\
\text { Percent }\end{array}$ \\
\hline \multirow{4}{*}{\begin{tabular}{l} 
Valid \\
\cline { 2 - 6 }
\end{tabular}} & LAKI- & 34 & 54.8 & 54.8 & 54.8 \\
\cline { 2 - 7 } & $\begin{array}{l}\text { PEREM } \\
\text { PUAN }\end{array}$ & 28 & 45.2 & 45.2 & 100.0 \\
\cline { 2 - 7 } & & 62 & & & \\
\hline
\end{tabular}

Sumber : Data diolah, 2018

b. Responden Berdasarkan Usia Umur responden yang terbanyak adalah berumur antara $>26-35$ tahun sebanyak 35 orang atau $37 \%$, diikuti dengan usia responden $<25$ tahun sebanyak 10 orang atau $16 \%$, diikuti dengan usia responden $>36-45$ tahun sebanyak 10 orang atau $16 \%$, diikuti dengan usia responden dengan usia > 46 tahun sebanyak 7 orang atau $11 \%$. Proporsi demikian menunjukkan adanya distribusi umur yang mencolok pada kisaran umur 26-35 tahun atau relatif muda.

\begin{tabular}{|c|l|r|r|r|r|}
\hline \multicolumn{7}{|c|}{ USIA } \\
\hline \multicolumn{7}{|c|}{} & Frequency & Percent & $\begin{array}{l}\text { Valid } \\
\text { Percent }\end{array}$ & \multicolumn{2}{l|}{$\begin{array}{l}\text { Cumulative } \\
\text { Percent }\end{array}$} \\
\hline \multirow{5}{*}{ Valid } & $<25$ & 10 & 16.1 & 16.1 & 16.1 \\
\cline { 2 - 6 } & $>26-35$ & 35 & 56.5 & 56.5 & 72.6 \\
\cline { 2 - 6 } & $>36-45$ & 10 & 16.1 & 16.1 & 88.7 \\
\cline { 2 - 6 } & $>46$ & 7 & 11.3 & 11.3 & 100.0 \\
\cline { 2 - 6 } & Total & 62 & & & \\
\hline
\end{tabular}

Sumber : Data diolah, 2018

c. Responden Berdasarkan Tingkat Pendidikan

Data responden berdasarkan tingkat pendidikan

\begin{tabular}{|l|l|r|r|r|r|}
\hline \multicolumn{7}{|c|}{ JENJANG PENDIDIKAN } \\
\hline \multicolumn{1}{|c|}{} & Frequency & Percent & $\begin{array}{l}\text { Valid } \\
\text { Perce }\end{array}$ & $\begin{array}{l}\text { Cumulative } \\
\text { Percent }\end{array}$ \\
\hline \multirow{5}{*}{ Valid } & SLTA & 2 & 3.2 & 3.2 & 3.2 \\
\cline { 2 - 6 } & D3 & 6 & 9.7 & 9.7 & 12.9 \\
\cline { 2 - 6 } & S1/S2 & 54 & 87.1 & 87.1 & 100.0 \\
\cline { 2 - 6 } & Total & 62 & & & \\
\hline
\end{tabular}

Sumber : Data diolah, 2018

Dari 62 responden yang dikumpulkan menunjukkan bahwa responden berpendidikan SMA sebanyak 2 orang atau 3\%, D3 sebanyak 6 orang atau $10 \%$, dan responden berpendidikan $\mathrm{S}_{1}$ / $\mathrm{S}_{2}$ sebanyak 54 orang atau $87 \%$. Dapat disimpulkan bahwa PT. Bank Sulselbar Kantor Pusat Makassar yang dominan ialah karyawan berpendidikan $\mathrm{S}_{1}$ / S2 .
d. Responden Berdasarkan Masa Bekerja 
Data responden berdasarkan masa bekerja

\begin{tabular}{|c|c|r|r|r|r|}
\hline \multicolumn{7}{|c|}{ LAMA BEKERJA } \\
\hline \multicolumn{1}{|c|}{} & Frequency & Percent & $\begin{array}{l}\text { Valid } \\
\text { Percent }\end{array}$ & $\begin{array}{l}\text { Cumulative } \\
\text { Percent }\end{array}$ \\
\hline \multirow{5}{*}{ Valid } & $1-5$ & 23 & 37.1 & 37.1 & 37.1 \\
\cline { 2 - 6 } & $6-10$ & 25 & 40.3 & 40.3 & 77.4 \\
\cline { 2 - 6 } & $>10$ & 14 & 22.6 & 22.6 & 100.0 \\
\cline { 2 - 6 } & Tota & 62 & & & \\
\hline
\end{tabular}

Sumber : Data diolah, 2018

Dari 62 responden yang dikumpulkan menunjukkan bahwa responden bekerja selama 1-5 tahun sebanyak 23 orang atau $37 \%$, responden yang bekerja selama 6-10 tahun sebanyak 25 orang atau $40 \%$, dan responden yang bekerja selama $>10$ tahun sebanyak 14 orang atau 23\%. Dari data tersebut dapat disimpulkan bahwa PT. Bank Sulselbar Kantor Pusat Makassar yang dominan ialah karyawan yang bekerja selama 6-10 tahun sebanyak 25 atau $40 \%$.

\section{Analisis Data}

\section{Uji Instrumen}

\section{1) Uji Validitas}

Uji validitas digunakan untuk menguji seberapa cermat suatu alat ukur dalam melakukan fungsi ukurannya. Pada penelitian ini, pengujian validitas dengan mengkorelasikan skor butir pada kuesioner dengan skor totalnya. Jika nilai koefisien korelasinya $<0,05$ maka butir pertanyaan tersebut dapat dikatakan valid.
a) Uji Validitas Mekanisme Transfer Ilmu (X1)

\section{Hasil Validitas Mekanisme Transfer Ilmu}

\begin{tabular}{|c|c|c|c|c|c|}
\hline \multicolumn{6}{|c|}{ Correlations } \\
\hline & & $\mathrm{X} 1.1$ & $\mathrm{X} 1.2$ & $\mathrm{X} 1.3$ & $\mathrm{X} 1$ \\
\hline \multirow{3}{*}{ X1.1 } & $\begin{array}{l}\text { Pearson } \\
\text { Correlation }\end{array}$ & 1 & .092 & $.376^{* *}$ & $.660^{* *}$ \\
\hline & $\begin{array}{l}\text { Sig. (2- } \\
\text { tailed) }\end{array}$ & & .476 & .003 & .000 \\
\hline & $\mathrm{N}$ & 62 & 62 & 62 & 62 \\
\hline \multirow{3}{*}{$\mathrm{X} 1.2$} & $\begin{array}{l}\text { Pearson } \\
\text { Correlation }\end{array}$ & .092 & 1 & $.632^{* *}$ & $.755^{* *}$ \\
\hline & $\begin{array}{l}\text { Sig. (2- } \\
\text { tailed) }\end{array}$ & .476 & & .000 & .000 \\
\hline & $\mathrm{N}$ & 62 & 62 & 62 & 62 \\
\hline \multirow[t]{3}{*}{$\mathrm{X} 1.3$} & $\begin{array}{l}\text { Pearson } \\
\text { Correlation }\end{array}$ & $.376^{* *}$ & $.632^{* *}$ & 1 & $.864^{* *}$ \\
\hline & $\begin{array}{l}\text { Sig. (2- } \\
\text { tailed) }\end{array}$ & .003 & .000 & & .000 \\
\hline & $\mathrm{N}$ & 62 & 62 & 62 & 62 \\
\hline \multirow[t]{3}{*}{$\mathrm{X} 1$} & $\begin{array}{l}\text { Pearson } \\
\text { Correlation }\end{array}$ & $.660^{* *}$ & $.755^{* *}$ & $.864^{* *}$ & 1 \\
\hline & $\begin{array}{l}\text { Sig. (2- } \\
\text { tailed) }\end{array}$ & .000 & .000 & .000 & \\
\hline & $\mathrm{N}$ & 62 & 62 & 62 & 62 \\
\hline
\end{tabular}


Instrumen kuesioner mekanisme transfer ilmu dinyatakan valid karena berada pada nilai signifikan $0,00<$ 0,05. Artinya, keseluruhan indikator penelitian dalam kuesioner mampu menjelaskan variabel mekanisme transfer ilmu.

b) Uji Validitas Sarana Pendukung (X2)

Hasil Validitas Sarana

\begin{tabular}{|c|c|c|c|c|c|}
\hline \multicolumn{6}{|c|}{ Correlations } \\
\hline & & $\mathrm{X} 2.1$ & $\mathrm{X} 2.2$ & $\mathrm{X} 2.3$ & $\mathrm{X} 2$ \\
\hline \multirow[t]{3}{*}{ X2.1 } & $\begin{array}{l}\text { Pearson } \\
\text { Correlation }\end{array}$ & 1 & $.561^{* *}$ & $466^{* *}$ & \\
\hline & Sig. (2-tailed) & & .000 & .000 & .000 \\
\hline & $\mathrm{N}$ & 62 & 62 & 62 & 62 \\
\hline \multirow[t]{3}{*}{$\mathrm{X} 2.2$} & \begin{tabular}{|l} 
Pearson \\
Correlation
\end{tabular} & $.561^{* *}$ & 1 & $.692^{* *}$ & $.909^{* *}$ \\
\hline & Sig. (2-tailed) & .000 & .000 & .000 & .000 \\
\hline & $\mathrm{N}$ & 62 & 62 & 62 & 62 \\
\hline \multirow[t]{3}{*}{$\mathrm{X} 2.3$} & \begin{tabular}{|l} 
Pearson \\
Correlation
\end{tabular} & $.466^{* *}$ & $.692^{* *}$ & 1 & $.866^{* *}$ \\
\hline & Sig. (2-tailed) & .000 & .000 & .000 & .000 \\
\hline & $\mathrm{N}$ & 62 & 62 & 62 & 62 \\
\hline \multirow[t]{4}{*}{$\mathrm{X} 2$} & $\begin{array}{l}\text { Pearson } \\
\text { Correlation }\end{array}$ & $.757^{* *}$ & $.909^{* *}$ & $.866^{* *}$ & 1 \\
\hline & & $\mathrm{X} 2.1$ & $\mathrm{X} 2.2$ & $\mathrm{X} 2.3$ & $\mathrm{x} 2$ \\
\hline & Sig. (2-tailed) & .000 & .000 & .000 & \\
\hline & $\mathrm{N}$ & 62 & 62 & 62 & 62 \\
\hline$* *$. & lation is signifi & it at the 0.0 & 1 level (2 & 2-tailed). & \\
\hline
\end{tabular}

Sumber : Data diolah, 2018

Instrumen kuesioner sarana pendukung dinyatakan valid karena berada pada nilai signifikan $0,00<$ 0,05 .

c) Uji Validitas Budaya Organisasi (X3)

Hasil Validitas Budaya Organisasi

\begin{tabular}{|c|c|c|c|c|c|}
\hline \multicolumn{6}{|c|}{ Correlations } \\
\hline & & X3.1 & X3.2 & X3.3 & $\mathrm{x} 3$ \\
\hline \multirow[t]{3}{*}{ X3.1 } & \begin{tabular}{|l} 
Pearson \\
Correlation
\end{tabular} & 1 & $.584^{* *}$ & $644^{* *}$ & $.875^{* *}$ \\
\hline & Sig. (2-tailed) & & .000 & .000 & .000 \\
\hline & $\mathrm{N}$ & 62 & 62 & 62 & 62 \\
\hline \multirow[t]{3}{*}{$\mathrm{X} 3.2$} & \begin{tabular}{|l} 
Pearson \\
Correlation
\end{tabular} & $.584^{* *}$ & 1 & $.554^{* *}$ & $.831^{* *}$ \\
\hline & Sig. (2-tailed) & .000 & & .000 & .000 \\
\hline & $\mathrm{N}$ & 62 & 62 & 62 & 62 \\
\hline \multirow[t]{3}{*}{$\mathrm{X} 3$} & \begin{tabular}{|l} 
Pearson \\
Correlation
\end{tabular} & $.644^{* *}$ & $.554^{* *}$ & 1 & $.856^{* *}$ \\
\hline & Sig. (2-tailed) & .000 & .000 & & .000 \\
\hline & $\mathrm{N}$ & 62 & 62 & 62 & 62 \\
\hline \multirow[t]{3}{*}{ X3 } & $\begin{array}{l}\text { Pearson } \\
\text { Correlation }\end{array}$ & $.875^{\star *}$ & $.831^{* *}$ & $.856^{* *}$ & 1 \\
\hline & Sig. (2-tailed) & .000 & .000 & .000 & \\
\hline & N & 62 & 62 & 62 & 62 \\
\hline$* * . \mathrm{C}$ & orrelation is sign & cant at the 0 & .01 level & (2-tailed). & \\
\hline
\end{tabular}

Sumber : Data diolah, 2018

Instrumen kuesioner budaya organisasi dinyatakan valid karena berada pada nilai signifikan $0,00<$ 0,05 . Artinya, keseluruhan indikator penelitian dalam kuesioner mampu menjelaskan variabel budaya organisasi.

d) Uji Validitas Motivasi (X4) Hasil Validitas Motivasi 


\begin{tabular}{|c|c|c|c|c|c|}
\hline \multicolumn{6}{|c|}{ Correlations } \\
\hline & & X4.1 & $\times 4.2$ & $\times 4.3$ & $\mathrm{X} 4$ \\
\hline \multirow[t]{3}{*}{ X4.1 } & \begin{tabular}{|l} 
Pearson \\
Correlation
\end{tabular} & 1 & $.331^{* *}$ & $.667^{* *}$ & $.782^{* *}$ \\
\hline & Sig. (2-tailed) & & .009 & .000 & .000 \\
\hline & $N$ & 62 & 62 & 62 & 62 \\
\hline \multirow[t]{3}{*}{$X 4.2$} & $\begin{array}{l}\text { Pearson } \\
\text { Correlation }\end{array}$ & $.331^{* *}$ & 1 & $.646^{* *}$ & $.810^{* *}$ \\
\hline & Sig. (2-tailed) & .009 & & .000 & .000 \\
\hline & $N$ & 62 & 62 & 62 & 62 \\
\hline \multirow[t]{3}{*}{$X 4.3$} & $\begin{array}{l}\text { Pearson } \\
\text { Correlation }\end{array}$ & $.667^{* *}$ & $.646^{* *}$ & 1 & $.914^{* *}$ \\
\hline & Sig. (2-tailed) & .000 & .000 & & .000 \\
\hline & $N$ & 62 & 62 & 62 & 62 \\
\hline \multirow[t]{3}{*}{ X4 } & $\begin{array}{l}\text { Pearson } \\
\text { Correlation }\end{array}$ & $.782^{* *}$ & $.810^{* *}$ & $.914^{* *}$ & 1 \\
\hline & Sig. (2-tailed) & .000 & .000 & .000 & \\
\hline & $N$ & 62 & 62 & 62 & 62 \\
\hline **. Co & ation is signi & at the & .01 level & (2-tailed) & \\
\hline
\end{tabular}

Sumber : Data diolah, 2018

Instrumen kuesioner motivasi dinyatakan valid karena berada pada nilai signifikan $0,00<0,05$. Artinya, keseluruhan indicator penelitian dalam kuesioner mampu menjelaskan variabel motivasi.

e) Uji Validitas Intensi Knowledge Sharing (Y)

Hasil Validitas Intensi Knowledge Sharing

\begin{tabular}{|c|c|c|c|c|c|}
\hline \multicolumn{6}{|c|}{ Correlations } \\
\hline & & Y1 & Y2 & Y3 & Y \\
\hline \multirow[t]{3}{*}{ Y1 } & $\begin{array}{l}\text { Pearson } \\
\text { Correlation }\end{array}$ & 1 & $.789^{* *}$ & $.714^{* *}$ & $.906^{* *}$ \\
\hline & Sig. (2-tailed) & & .000 & .000 & .000 \\
\hline & N & 62 & 62 & 62 & 62 \\
\hline \multirow[t]{3}{*}{ Y2 } & $\begin{array}{l}\text { Pearson } \\
\text { Correlation }\end{array}$ & $.789^{* *}$ & 1 & $.796^{\star *}$ & $.945^{* *}$ \\
\hline & Sig. (2-tailed) & .000 & & .000 & .000 \\
\hline & N & 62 & 62 & 62 & 62 \\
\hline \multirow[t]{3}{*}{ Y3 } & $\begin{array}{l}\text { Pearson } \\
\text { Correlation }\end{array}$ & $.714^{* *}$ & $.796^{* *}$ & 1 . & $.906^{* *}$ \\
\hline & Sig. (2-tailed) & .000 & .000 & & .000 \\
\hline & N & 62 & 62 & 62 & 62 \\
\hline \multirow[t]{3}{*}{$\mathrm{Y}$} & $\begin{array}{l}\text { Pearson } \\
\text { Correlation }\end{array}$ & $.906^{* *}$ & $.945^{* *}$ & $.906^{* *}$ & 1 \\
\hline & Sig. (2-tailed) & .000 & .000 & .000 & \\
\hline & N & 62 & 62 & 62 & 62 \\
\hline & elation is signifi & th at the 0.0 & 01 level ( & 2-tailed). & \\
\hline
\end{tabular}

Sumber : Data diolah, 2018

Instrumen kuesioner intensi knowledge sharing karyawan dinyatakan valid karena berada pada nilai signifikan $0,00<0,05$. Artinya, keseluruhan indikator penelitian dalam kuesioner mampu menjelaskan variabel intensi knowledge sharing karyawan.

2) Uji Reliabilitas

Uji reliabilitas instrumen dilakukan dengan menggunakan rumus Cronbach Alpha dengan asumsi bahwa suatu instrumen dianggap reliabel apabila memiliki nilai Cronbach's Alpha >0,60. 
Hasil Uji Reliabilitas

\begin{tabular}{|c|c|c|c|}
\hline Variabel & $\begin{array}{l}\text { Cronbach } \\
\text { Alpha }\end{array}$ & $\begin{array}{l}\text { Standar } \\
\text { Cronbach } \\
\text { Alpha }\end{array}$ & Ket. \\
\hline $\begin{array}{l}\text { Mekanisme } \\
\text { transfer ilmu }\end{array}$ & 0,616 & 0,60 & Reliabel \\
\hline $\begin{array}{l}\text { Sarana } \\
\text { pendukun } \\
g\end{array}$ & 0,799 & 0,60 & Reliabel \\
\hline $\begin{array}{l}\text { Buday } \\
\text { a } \\
\text { organisa } \\
\text { i }\end{array}$ & 0,815 & 0,60 & Reliabel \\
\hline Motivasi & 0,774 & 0,60 & Reliabel \\
\hline \begin{tabular}{|l} 
Intensi \\
knowled \\
ge \\
sharing
\end{tabular} & 0,906 & 0,60 & Reliabel \\
\hline
\end{tabular}

Semua item pernyataan yang diajukan sudah reliabel atau handal, hal ini dapat dilihat dari variabel mekanisme transfer ilmu memiliki nilai Cronbach Alpha 0,616, variabel sarana pendukung memiliki nilai Cronbach Alpha 0,799, variabel budaya organisasi memiliki nilai Cronbach Alpha 0,815, variabel motivasi memiliki nilai Cronbach Alpha 0,774, dan variabel intensi knowledge sharing karyawan memiliki nilai Cronbach Alpha 0,906, sehingga dapat disimpulkan bahwa semua variabel sudah handal karena memiliki nilai Cronbach's Alpha> 0,60 .

\section{b) Analisis Regresi Linear Berganda}

Hasil Analisis Regresi Linear Berganda

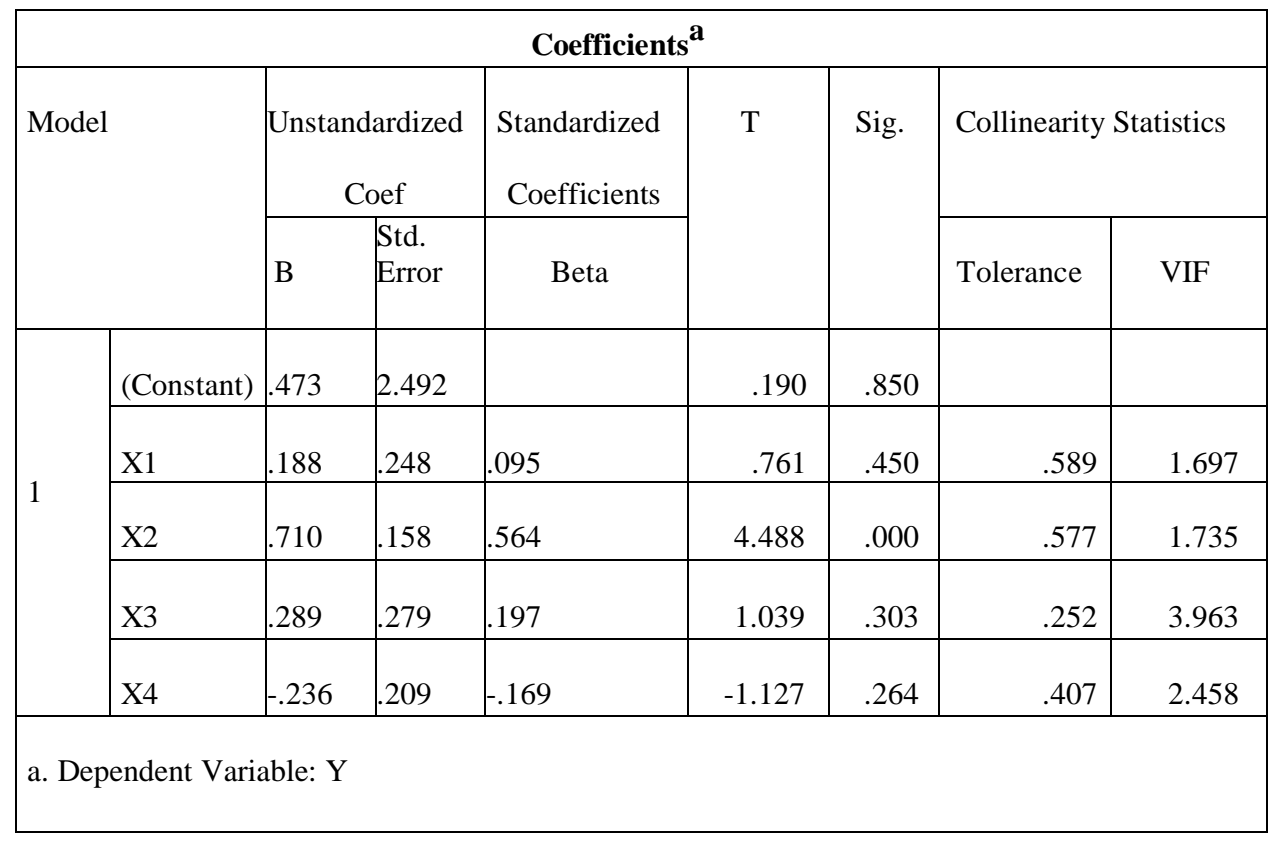

Dalam bentuk persamaan regresi bentuk Standardized Coefficients diperoleh persamaan sebagai berikut:

$\mathrm{Y}=0,437+0,188 \mathrm{X}_{1}+0,710 \mathrm{X}_{2}$

$+0,289 X_{3}-0,236 X_{4}$

Adapun interpretasi dari regresi di atas sebagai berikut:
1) Nilai konstanta (a) sebesar 0,437 bernilai positif artinya menunjukkan pengaruh positif pada variabel independen, yakni mekanisme transfer ilmu (X1), sarana pendukung (X2), budaya (X3), dan motivasi (X4). Jika variabel independen (X1), (X2), (X3), dan (X4) 
sama dengan nol maka nilai intensi knowledge sharing sama dengan konstanta 0,437.

2) Koefisien regresi

mekanisme trasfer ilmu (X1) memiliki nilai sebesar 0,188 , menyatakan bahwa mekanisme trasfer ilmu memiliki pengaruh positif terhadap intensi knowledge sharing pada PT. Bank Sulselbar Kantor Pusat Makassar.

3) Koefisien regresi (b2) sarana pendukung (X2) memiliki nilai sebesar 0,710, menyatakan bahwa sarana pendukung memiliki pengaruh positif terhadap intensi knowledge sharing pada PT. Bank Sulselbar Kantor Pusat Makassar.

4) Koefisien regresi (b3) budaya (X3) memiliki nilai sebesar 0,289, menyatakan budaya memiliki pengaruh positif terhadap intensi knowledge sharing pada PT. Bank Sulselbar Kantor Pusat Makassar.

5) Koefisien regresi (b4) motivasi (X4) memiliki nilai -0,236, menyatakan bahwa motivasi memiliki pengaruh negatif terhadap intensi knowledge sharing pada PT. Bank Sulselbar Kantor Pusat Makassar.
Dari hasil interpretasi regresi, maka dapat disimpulkan bahwa sarana pendukung yang lebih mampu mempengaruhi tingkat intensi knowledge sharing pada PT. Bank Sulselbar Kantor Pusat Makassar sebesar $71 \%$.

\section{c) Uji Hipotesis Penelitian}

Untuk mengetahui kebenaran hipotesis, maka harus terlebih dahulu memenuhi uji multikolinieritas. Pengujian ini dilakukan agar hipotesis yang diuji dapat disimpulkan sebagai dasar pengambilan keputusan. Pengujian hipotesis yang akan diuji menggunakan uji parsial (Uji t), sebagai berikut:

1) Parsial (Uji t)

Uji $t$ statistik pada dasarnya menunjukkan seberapa jauh pengaruh suatu variabel independen secara parsial dalam menerankan variasi variabel dependen (Ghozali, 2005). Apabila nilai signifikan lebih kecil 0,05 atau $5 \%$ maka suatu variabel independen secara parsial mempengaruhi variabel dependen. Dengan kata lain, suatu variabel independen merupakan penjelasan yang signifikan terhadap variabel dependen. Adapu hasil uji signifikan (Uji t) berikut ini.

Tabel 4.12

Hasil Uji Signifikansi Individual (Uji t)






\begin{tabular}{|l|l|l|l|l|r|r|r|r|}
\hline & $\mathrm{X} 2$ & .710 & .158 & .564 & 4.488 & .000 & .577 & 1.735 \\
\cline { 2 - 8 } & $\mathrm{X} 3$ & .289 & .279 & .197 & 1.039 & .303 & .252 & 3.963 \\
\cline { 2 - 8 } & $\mathrm{X} 4$ & -.236 & .209 & -.169 & -1.127 & .264 & .407 & 2.458 \\
\hline
\end{tabular}

Sumber : Data diolah, 2018

Dari hasil pengolahan data uji signifikansi maka dapat dijelaskan sebagai berikut:

a) Mekanisme transfer ilmu (X1) terhadap intense knowledge sharing (Y)

Menunjukkan hasil pengujian regresi untuk variabel mekanisme transfer ilmu terhadap intensi knowledge sharing dengan nilai thitung sebesar 0,761 dan nilai signifikansi 0,450 $>0,05$. Hal ini menunjukka bahwa mekanisme transfer berpengaruh secara positif dan tidak signifikan terhadap intensi knowledge sharing pada PT. Bank Sulselbar Kantor Pusat Makassar.

b) Sarana pendukung (X2) terhadap intense knowledge sharing (Y)

Menunjukkan hasil pengujian regresi untuk variabel sarana pendukung terhadap intense knowledge sharing dengan nilai thitung sebesar 4,488 dan nilai signifikansi $0,000<0,05$. Hal ini menunjukka bahwa sarana pendukung berpengaruh secara positif dan signifikan terhadap intensi knowledge sharing pada PT. Bank Sulselbar Kantor Pusat Makassar.

c) Budaya (X3) terhadap intensi knowledge sharing $(\mathrm{Y})$
Menunjukkan hasil pengujian regresi untuk variabel budaya terhadap intensi knowledge sharing dengan nilai thitung sebesar 1,039 dan nilai signifikansi $0,303>0,05$. Hal ini menunjukka bahwa budaya berpengaruh secara positif dan tidak signifikan terhadap intensi knowledge sharing pada PT. Bank Sulselbar Kantor Pusat Makassar.

d) Motivasi (X4) terhadap intensi knowledge sharing $(\mathrm{Y})$

Menunjukkan hasil pengujian regresi untuk variabel motivasi terhadap intensi knowledge sharing dengan nilai thitung sebesar 1,127 dan nilai signifikansi $0,264>0,05$. Hal ini menunjukka bahwa motivasi berpengaruh secara negatif dan tidak signifikan terhadap intensi knowledge sharing pada PT. Bank Sulselbar Kantor Pusat Makassar.

d) Uji Asumsi Klasik

1) Uji normalitas

Uji normalitas yang dilakukan terhadap sampel dilakukan dengan menggunakan Probability Plot. jika sebaran data mendekati garis normal atau di sekitar garis diagonal dan mengikuti arah garis diagonal, sehingga dapat disimpulkan 
bahwa data mempunyai distribusi normal (Ghozali, 2007 : 140).



Berdasarkan uji normalitas dengan menggunakan bantuan spss terlihat dari grafik di atas penyebaran data (titik) pada sumbu diagonal mengikuti arah garis diagonal sehingga dapat disimpulkan bahwa model regresi memenuhi asumsi normalitas

2) Uji multikolinieritas

Adanya multikolinieritas dapat dilihat dari tolerence value > 0,01 dan nilai varience inflation factor $(V I F)<10$.

Sumber : Lampiran SPSS / Diolah, 2018

Uji Multikolinieritas

\begin{tabular}{|c|c|c|c|c|c|c|c|c|}
\hline \multicolumn{9}{|c|}{ Coefficients $^{\mathbf{a}}$} \\
\hline \multirow{3}{*}{\multicolumn{2}{|c|}{ Model }} & \multirow{2}{*}{\multicolumn{2}{|c|}{$\begin{array}{c}\text { Unstandardized } \\
\text { Coef }\end{array}$}} & \multirow{2}{*}{$\begin{array}{c}\text { Standardized } \\
\text { Coefficients } \\
\text { Beta }\end{array}$} & \multirow[t]{2}{*}{$\mathrm{T}$} & \multirow[t]{2}{*}{ Sig. } & \multicolumn{2}{|c|}{ Collinearity Statistics } \\
\hline & & & & & & & & \\
\hline & & B & $\begin{array}{l}\text { Std. } \\
\text { Error }\end{array}$ & & & & Tolerance & VIF \\
\hline \multirow{5}{*}{1} & (Constant) & .473 & 2.492 & & .190 & .850 & & \\
\hline & $\mathrm{X} 1$ & .188 & .248 & .095 & .761 & .450 & .589 & 1.697 \\
\hline & $\mathrm{X} 2$ & .710 & .158 & .564 & 4.488 & .000 & .577 & 1.735 \\
\hline & $\mathrm{X} 3$ & .289 & .279 & .197 & 1.039 & .303 & .252 & 3.963 \\
\hline & $\mathrm{X} 4$ & -.236 & .209 & -.169 & -1.127 & .264 & .407 & 2.458 \\
\hline
\end{tabular}

Sumber : Data diolah, 2018

Masing- masing variabel independen memiliki nilai VIF $<10$ dan nilai tolerance $>0,01$ maka dapat disimpulkan bahwa model regresi untuk mekanisme transfer, sarana pendukung, budaya, dan motivasi tidak terdapat multikolinieritas dan modal regresi layak untuk digunakan.

\section{Pembahasan}

1. Pengaruh transfer ilmu mekanisme intensi knowledge sharing pada PT. Bank Sulselbar Kantor Pusat Makassar.

Berdasarkan hasil pengujian secara parsial yang telah dilakukan, diperoleh hasil yang menyatakan bahwa mekanisme transfer ilmu (C) 2020 STIE TDN. All rights reserved 
berpengaruh positif dan tidak signifikan terhadap intensi knowledge sharing dengan nilai signifikansi yang diperoleh sebesar 0,450, maka keputusannya menerima hipotesis pertama. Hasil penelitian ini sejalan dengan penelitian yang dilakukan oleh Abdul-Jalal dkk (2013) menunjukkan bahwa opportunity to share knowledge (kesempatan untuk berbagi knowledge) berpengaruh secara positif dan tidak signifikan terhadap intensi knowledge sharing.

2. Pengaruh sarana pendukung terhadap intensi knowledge sharing pada PT. Bank Sulselbar Kantor Pusat Makassar.

Sarana pendukung berpengaruh positif dan signifikan terhadap intensi knowledge sharing dengan nilai signifikansi yang diperoleh sebesar 0,000, maka keputusannya menolak hipotesis kedua. Hal tersebut disebabkan karena sarana pendukung atau fasilitas yang ada pada PT. Bank Sulselbar Kantor Pusat Makassar sudah memadai, Sehingga dapat disimpulkan bahwa fasilitas internet dapat dijadikan sebagai sarana komunikasi yang efektif dalam berbagi ilmu pengetahuan. Hasil penelitian ini sejalan dengan penelitian yang di lakukan oleh Supar (2012) yang menunjukkan bahwa keberadaan teknologi informasi untuk knowledge sharing berpengaruh positif dan signifikan terhadap intensi knowledge sharing.

3. Pengaruh budaya terhadap intensi knowledg sharing pada PT. Bank Sulselbar Kantor Pusat Makassar.

Budaya berpengaruh positif dan tidak signifikan terhadap intensi knowledge sharing dengan nilai signifikansi yang diperoleh sebesar 0,303, maka keputusannya menerima hipotesis keketiga. Hal tersebut diakibatkan karena budaya organisasi merupakan nilai yang telah lama ada dan tidak dapat berubah dalam waktu yang cepat. Hasil penelitian ini sejalan dengan penelitian yang di lakukan oleh Borges (2013) menunjukkan bahwa budaya organisasi yang berpengaruh positif dan tidak signifikan terhadap intensi knowledge sharing.

4. Pengaruh motivasi terhadap intensi knowledge sharing pada PT. Bank Sulselbar Kantor Pusat Makassar.

Motivasi berpengaruh negatif dan tidak signifikan terhadap intensi knowledge sharing dengan nilai signifikansi yang diperoleh sebesar 0,264, maka keputusannya menolak hipotesis keempat. Hal tersebut diakibatkan karena kurangnya komunikasi non formal seperti diskusi membahas hal diluar pekerjaan sehingga menyebabkan hubungan emosional tidak terjalin dengan baik.

5. Faktor yang paling dominan mempengaruhi intensi knowledge sharing pada PT. Bank Sulselbar Kantor Pusat Makassar.

Faktor yang paling dominan berpengaruh terhadap intense knowledge sharing pada PT. Bank Sulselbar Kantor Pusat Makassar adalah sarana pendukung, hal ini disebabkan karena sarana pendukung memiliki nilai koefisien beta terbesar sebesar 0,564 serta memiliki nilai probabilitas 0,000 yang terkecil jika dibandingkan dengan faktor lainnya, dimana semakin kecil probabilitas maka semakin besar pengaruhnya terhadap intensi knowledge sharing. Dari hasil penelitian ini, maka hipotesis kelima diterima yang menyatakan bahwa faktor yang paling dominan mempengaruhi intensi knowledge sharing pada PT. Bank Sulselbar 
Kantor Pusat Makassar adalah sarana pendukung.

\section{KESIMPULAN DAN SARAN}

\section{Kesimpulan}

Berdasarkan uraian-uraian yang telah diungkapkan pada pembahasan, maka dapat diambil beberapa kesimpulan sebagai jawaban atas pokok permasalahan yang diajukan dalam penelitian ini, yaitu:

1. Dalam pengujian secara parsial variabel mekanisme transfer ilmu (X1) berpengaruh secara positif dan tidak signifikan terhadap intensi knowledge sharing pada PT. Bank Sulselbar Kantor Pusat Makassar.

2. Dalam pengujian secara parsial variabel sarana pendukung (X2) berpengaruh secara positif dan signifikan terhadap intensi knowledge sharing pada PT. Bank Sulselbar Kantor Pusat Makassar.

3. Dalam pengujian secara parsial variabel budaya (X3) berpengaruh secara positif dan tidak signifikan terhadap intensi knowledge sharing pada PT. Bank Sulselbar Kantor Pusat Makassar.

4. Dalam pengujian secara parsial variabel motivasi (X4) berpengaruh secara negatif dan tidak signifikan terhadap intensi knowledge sharing pada PT. Bank Sulselbar Kantor Pusat Makassar.

5. Berdasarkan hasil pengujian regresi maka dapat diketahui bahwa faktor yang paling dominan berpengaruh terhadap intensi knowledge sharing pada PT. Bank Sulselbar Kantor Pusat Makassar adalah sarana pendukung.

\section{Saran}

Berdasarkan hasil penelitian dan kesimpulan, maka penulis akan memberikan beberapa saran kepada:

\section{Bagi pihak bank}

Berdasarkan kesimpulan

diatas, disarankan agar perlunya perusahaan PT. Bank Sulselbar Kantor Pusat Makassar untuk senantiasa melakukan program pendidikan dan pelatihan dua kali dalam setahun yang ditujukan kepada karyawannya terkhusus kepada karyawan baru, hal ini dimaksudkan agar pengetahuan dan keterampilan yang dimiliki oleh karyawan akan semakin meningkat.

\section{Bagi peneliti selanjutnya}

Disarankan untuk peneliti selanjutnya agar dapat meneliti faktorfaktor lain yang mempengaruhi intensi knowledge sharing, mengingat bahwa masih ada sisa $52 \%$.

\section{DAFTAR PUSTAKA}

Abdul-Jalal H. \& Toulson P. 2013. Knowledge Sharing Success for Sustaining Organizational Competitive Advantage. Procedia Economics and Finance. Vol. 7. 150-157.

Borges R. 2013. Tacit Knowledge

Sharing Between IT Workers. Management Research Review. Vol. 36(1). 89-10.

Goel A. Rana G, Rastogi R, 2010. Knowledge Management as a Process to Develop Sustainable Competitive Advantage. South Asian Journal of Management, 17(3) :104.

Gozali Iman. 2006. Aplikasi Analisis Multivariate dengan Program SPSS, edisi keempat, Badan Penerbit: Universitas Diponegoro, Semarang. 2007. Aplikasi Analisis Multivariate dengan Program SPSS, Badan Penerbit : 
Universitas

Diponegoro,

diakses pada tanggal

25

Semarang.

Januari 2018

Hoof, B dan Ridder J A. 2004.

Knowledge sharing in

context: The influence of

organizational commitment,

communication climate and

CMC use on knowledge

sharing. Journal of

knowledge management.

Jacobson A. 2006. Radiographic

Cephalometry from Basics to

Video- imaging Quintessence

Publishing Co.Inc.,

Alabama;1995:124-6.

Lopez JEN, Verde MD, Castro

GM. 2011. Organisational

Knowledge. Assets and

Innovation Capability.

Journal of Intellectual

Capital, 12(1) : 51-19.

Sugiyono. 2005. Memahami

Penelitian Kualitatif.

Penerbit Alfabeta

Bandung.

Supar N. 2012. Technological Factors Affecting Knowledge Sharing among Academic Staff in Selected Malaysian Higher Educational Institutions and the Effect on Performance. Journal of Education and Vocational Research. Vol. 3(7). 234-24

Szulanski G. 2001. Exploring Internal Stickiness: Impediments to the Transfer of Best Practice Within the Firm. Strategic Management Journal, Vol. 17, (Winter, 1996), 27-43.

http://y2n.staff.fkip.uns.ac.id/files/20

09/02/implementasi-

knowledge management. pdf diakses pada tanggal 25 Januari 2018

http://jurnal.pdii.lipi.go.id/admin/jurn al/71105971_18298176. pdf 